Research Article

\title{
Prevalence of Premenstrual Syndrome and Various Coping Strategies Used by Students in South India
}

\author{
Bissy B Treesa ${ }^{1 *}$, Ashmin Akbar ${ }^{1}$, Abijith Suresh ${ }^{1}$, Ranjith Raju${ }^{1}$, Infant Smily Alphonse ${ }^{2}$, Subadhra Devi J3 ${ }^{3}$, Venkatanarayanan $\mathrm{R}^{4}$ \\ ${ }^{1}$ Pharm D Interns, RVS College of Pharmaceutical Sciences, Coimbatore, Tamilnadu, India. \\ ${ }^{2}$ Assistant Professor, Department of Pharmacy Practice, RVS College of Pharmaceutical Sciences, Coimbatore, Tamilnadu, India. \\ ${ }^{3}$ Assistant Professor and Head, Department of Pharmacy Practice, RVS College of Pharmaceutical Sciences, Coimbatore, Tamilnadu, India. \\ ${ }^{4}$ Principal, RVS College of Pharmaceutical Sciences, Coimbatore, Tamilnadu, India. \\ *Corresponding author's E-mail: bissybtreesa@gmail.com
}

Received: 08-10-2021; Revised: 23-12-2021; Accepted: 27-12-2021; Published on: 15-01-2022.

\section{ABSTRACT}

Premenstrual syndrome is a cyclic phenomenon of somatic and effective symptoms occurs during their secretory phase of each menstrual cycle. These symptoms are of unknown aetiology and are not related to any organic lesions in the pelvic cavity. Although, the condition is not life-threatening, it can seriously decrease the quality of life of many women affecting mental health and their productivity. The objective of the study is to assess the prevalence of premenstrual syndrome and to identify its interfered factors and coping behaviors among the college students of South India. A questionnaire-based online survey was conducted for six months among the college students of South India. A total of 225 samples were collected by preparing and distributing the questionnaire forms and the assessment was done based on the Diagnostic Criteria published by the American College of Obstetricians and Gynaecologists. The prevalence of premenstrual syndrome was found to be $40 \%$. The most experienced somatic symptom was angry outbursts (50.7\%), and the effective symptom was found to be joint and muscle pain (50\%). About $39 \%$ of the participants had experienced significant negative associations with their educational activities. Lying down using a pillow (53.8\%) and drinking hot/cold drinks (37.8\%) were the most commonly used coping strategies. Educational sessions and seminars should be conducted to promote awareness among young women to follow proper coping measures to overcome premenstrual syndrome and to incorporate slight changes in lifestyle, diet modification, and physical activities to decrease the prevalence of PMS.

Keywords: Premenstrual Syndrome, Premenstrual symptoms, Prevalence, Interfered factors, Coping Behaviours.

QUICK RESPONSE CODE $\rightarrow$

DOI:

10.47583/ijpsrr.2022.v72i01.020

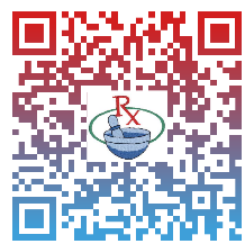

DOI link: http://dx.doi.org/10.47583/ijpsrr.2022.v72i01.020

\section{INTRODUCTION}

$\mathrm{M}$ enstruation is a normal physiological phenomenon in a women's reproductive life. ${ }^{1}$ Premenstrual syndrome (PMS) is a cyclic phenomenon of somatic and affective symptoms appearing in the days preceding menses and interfering with one's work or lifestyle followed by a symptom-freeinterval. ${ }^{2}$ The American College of Obstetricians and Gynaecologists (ACOG) defines PMS as a clinical condition characterized by the cyclic presence of physical and emotional symptoms unrelated to any organic disease that appear at least 5 days before menses in each of the three prior menstrual cycles and disappear within 4 days of the onset of menses, without recurrence until at least cycle day $13 .^{3}$

It has been estimated that the prevalence of premenstrual syndrome (PMS) is significantly higher among unmarried women and among women under low socioeconomic group living in socially deprived areas. ${ }^{4,5}$ Previous studies in India reported a prevalence of PMS to be $20-32 \%$ in premenopausal women and $30-40 \%$ of the reproductive female population and severe symptoms in $3-8 \%$ women. ${ }^{6-8}$

Although, there is no specific physical findings or laboratory test can be utilized to make the diagnosis of PMS, The American College of Obstetrics and Gynecology (ACOG) put forward a criterion that consists of any one of the Affective symptoms (Depression, Angry outbursts, Irritability, Anxiety, Confusion, and Social withdrawal) and Somatic symptoms (Breast tenderness, Abdominal bloating, Headache, Joint and Muscle Pain and Swelling of extremities) and it is shown in Table 1., ${ }^{9,10}$ These abovementioned symptoms should occur in the three prior menstrual cycles at least 5 days before the onset of menses and must resolve within 4 days of onset of menses and never recur until after day 12 of the cycle. The symptoms must adversely affect social or work-related activities. ${ }^{11}$ These conditions are not life-threatening but they can seriously decrease the quality of life of many women and affect their mental health and their productivity. ${ }^{12}$ It is estimated that up to $85 \%$ of women who menstruate experience at least one premenstrual symptom, occurring within 2 weeks before menses and easing after menses begins. ${ }^{13}$ Therefore, the following study is planned to provide information peculiar to the South Indian population by a large sample of university students, regarding the prevalence of PMS, along with its 
consequences on the quality of life and their coping behaviors.

\section{MATERIALS AND METHODS}

\section{Study Design}

A questionnaire-based online survey is conducted for six months among the college students of South India. A total of 225 samples were collected by preparing and distributing the questionnaire forms and the assessment is done based on the Diagnostic Criteria published by the American College of Obstetricians and Gynecologists.

\section{Inclusion Criteria}

PMS self-evaluation questionnaire form is sent to the undergraduate and postgraduate female students of South India via e-mail link. All responses are documented and screened for inclusion criteria.

\section{Exclusion Criteria}

The absence of menses (Pregnancy and Lactating women) and women with irregular menstrual cycles are excluded from the study. Women with a history of chronic diseases and history of Drug or Alcohol abuse are eliminated.

\section{Source of data}

A structured questionnaire form is developed to collect information about demographic details, health and medication-related characteristics, Clinical diagnosis, Clinical variables such as age at menarche, menstrual interval and duration of menstrual flow, PMS symptoms related to affective and somatic domains of quality of lifebased and its coping measures.

\section{Method of Assessment}

PMS Self Evaluation Questionnaire (PEQ) is applied to analyze the prevalence of PMS and American College of Obstetricians and Gynecologists (ACOG) Diagnostic criteria for PMS (Table 1) are used as a tool to assess PMS symptoms based on two domains namely affective symptoms and somatic symptoms.

Table 1: ACOG Diagnostic Criteria for Premenstrual Syndrome.

Premenstrual syndrome can be diagnosed if the patient reports at least one of the following affective and somatic symptoms during the five days before menses in each of the three previous menstrual cycles*

\begin{tabular}{l|l}
\hline Affective symptoms & Somatic symptoms \\
\hline Angry outbursts & Abdominal bloating \\
\hline Anxiety & Breast tenderness or swelling \\
\hline Confusion & Headache \\
\hline Depression & Joint or muscle pain \\
\hline Irritability & Swelling of extremities \\
\hline Social withdrawal & Weight gain \\
\hline
\end{tabular}

These symptoms must be relieved within four days of the onset of menses, without recurrence until at least day 13 of the cycle, and must be present in the absence of any pharmacologic therapy, hormone ingestion, or drug or alcohol use. The symptoms must occur reproducibly during two cycles of prospective recording. The patient must exhibit identifiable dysfunction in social, academic, or work performance.

Adapted with permission from American College of Obstetricians and Gynecologists. Guidelines for Women's Health Care: A Resource Manual. $4^{\text {th }}$ ed. Washington, DC: American College of Obstetricians and Gynecologists; 2014:608.

\section{RESULTS}

Clinical variables (Table 2 ) reveal that 17 (7.6\%) attained menarche before 12 years of age, whereas 202 (89.7\%) students attained menarche at the age between 12 and 15 years. However, around $6(2.7 \%)$ students attained menarche after 15 years. Considering the duration of menstrual flow, 28 (12.4\%) students had less than 3 days, 155 (68.9\%) had menstrual flow for the duration of 3-5 days and $42(18.7 \%)$ students had more than 5 days. Regarding menstrual interval, 8 (3.6\%) of them had less than 24 days, $214(95.1 \%)$ had menstrual interval of $24-35$ days and 3 (1.3\%) had more than 35 days.

Table 2: Distribution of students according to clinical variables regarding menstruation.

\begin{tabular}{|l|c|c|}
\hline Variables & $\begin{array}{c}\text { No of Students } \\
\text { (n=225) }\end{array}$ & $\begin{array}{c}\text { Percentage } \\
\text { (\%) }\end{array}$ \\
\hline Age At Menarche & & \\
\hline Before 12 years & 17 & $7.6 \%$ \\
\hline $12-15$ years & 202 & $89.7 \%$ \\
\hline After 15 years & 6 & $2.7 \%$ \\
\hline Duration of Typical Period & & \\
\hline$<3$ days & 28 & $12.4 \%$ \\
\hline $3-5$ days & 155 & $68.9 \%$ \\
\hline$>5$ days & 42 & $18.7 \%$ \\
\hline Menstrual Interval & & \\
\hline$<24$ days & 8 & $3.6 \%$ \\
\hline $24-35$ days & 214 & $95.1 \%$ \\
\hline$>35$ days & 3 & $1.3 \%$ \\
\hline
\end{tabular}

The PMS symptoms were classified into affective and somatic symptoms. Out of 225 students, a total of 193 students were symptomatic, the most common symptoms reported were angry outbursts 114 (50.7\%), followed by Joint and muscle pain 101 (44.9\%), irritability 91(40.4\%), depression 71 (31.6\%), headache 66 (29.3\%), abdominal bloating $61(27.1 \%)$, anxiety $59(26.2 \%)$, confusion 46 (20.4\%), breast tenderness or swelling $30(13.3 \%)$, social withdrawal $25(11.1 \%)$, weight gain $8(3.6 \%)$, swelling of extremities $5(2.2 \%)$, and $32(14.2 \%)$ students were 
asymptomatic (Figure 1).

Analysis revealed that, among 225 college students, 90 (40\%) students met with the diagnostic criteria for PMS, 114 (50.7\%) students just showed some symptoms and 21 $(9.3 \%)$ students did not show any symptoms at all (Figure 2).

A total of 145 students reported, at least, one area of impaired functioning. 88 (39.1\%) students were reluctant to engage in studies, $62(27.6 \%)$ students disinclined to cope with their home responsibilities, $57(25.3 \%)$ students felt difficulty while doing their work, 52 (23.1\%) students got interfered in relationship with others, $42(18.7 \%)$ students felt difficult in performing their social activities and $80(35.6 \%)$ students were not interfered with any activities (Figure 3 ).

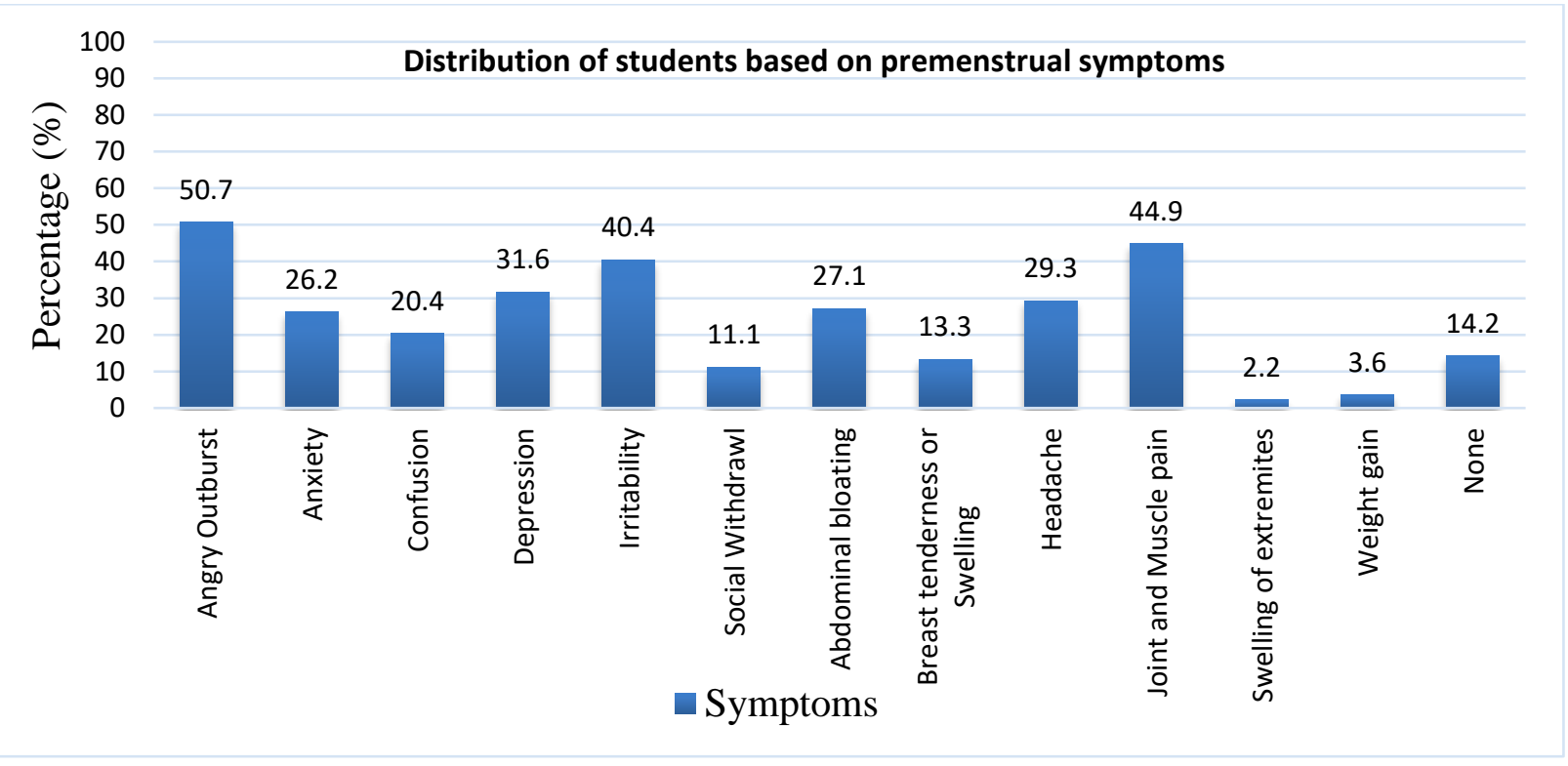

Figure 1: Distribution of students based on premenstrual symptoms.

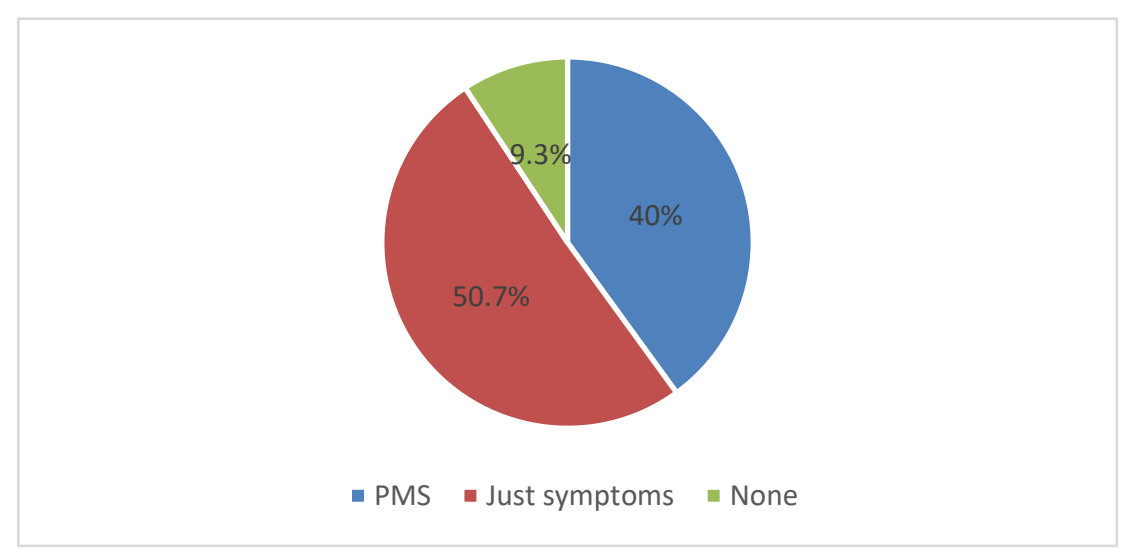

Figure 2: Prevalence of PMS.

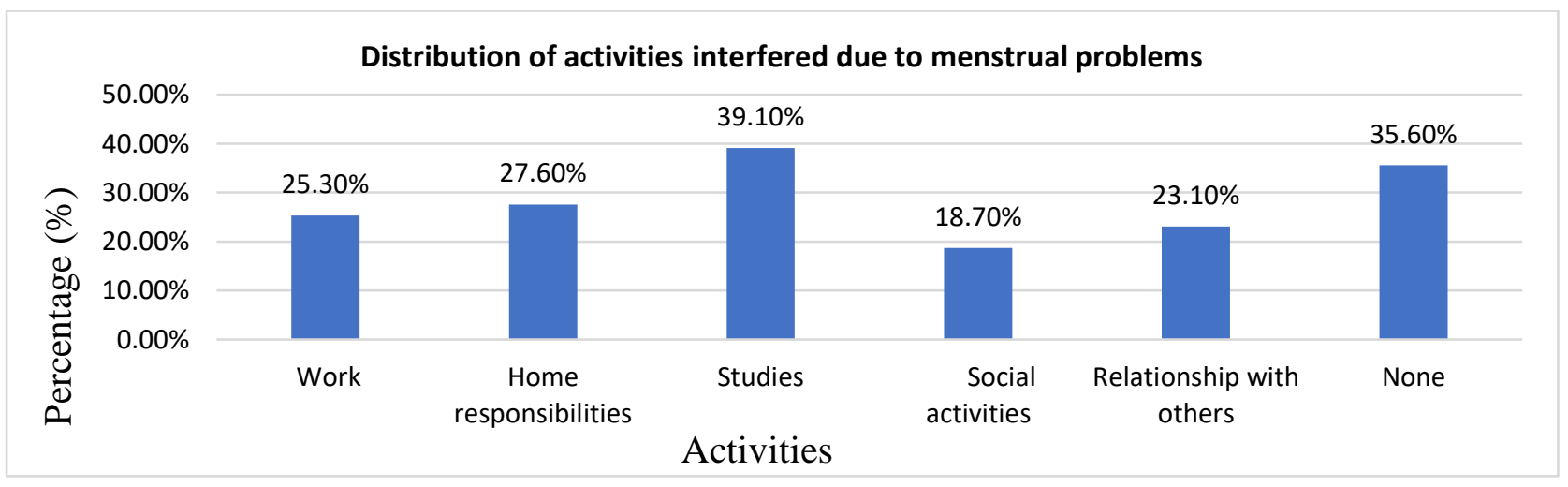

Figure 3: Distribution of activities interfered due to menstrual problems. 
Regarding coping behaviors used to overcome the premenstrual problems, out 225 participants, 173 mentioned various mechanisms by which they handle these symptoms. The most commonly used measures were lie down using pillow 121 (53.8\%), taking hot/cold drink, 85 (37.8\%), hot bags 56 (24.9\%), lying in fetal position 54 (24\%), NSAIDS/Painkillers 25 (11.1\%), others $3(1.3 \%)$ and $52(23.1 \%)$ students accepted PMS as natural process. (Figure 4).

\begin{tabular}{|c|c|c|c|c|c|c|c|}
\hline \multirow{6}{*}{ 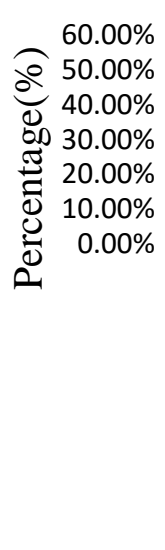 } & \multicolumn{6}{|c|}{ Distribution of coping behaviours to overcome the premberstyal problems } & \\
\hline & $37.80 \%$ & & & & & & \\
\hline & & & $4.90 \%$ & $24 \%$ & & $23.10 \%$ & \\
\hline & & $11.10 \%$ & & & & & \\
\hline & & & & & & & $1.30 \%$ \\
\hline & 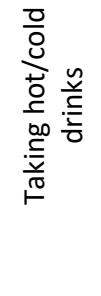 & 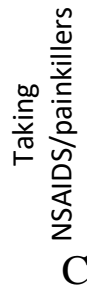 & 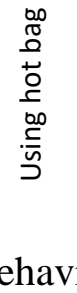 & 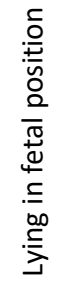 & 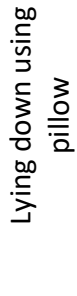 & 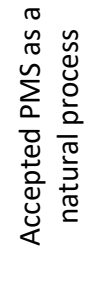 & $\begin{array}{l}\frac{n}{0} \\
\frac{1}{ \pm} \\
0\end{array}$ \\
\hline
\end{tabular}

Figure 4: Distribution of coping behaviours to overcome the premenstrual problems.

\section{DISCUSSION}

In our study, the prevalence of PMS was found to be $40 \%$, which was determined by applying PMS self-evaluation tool and ACOG criteria. A study in sub urban area of West Bengal reported a similar trend with the prevalence of PMS of about $54 \% .{ }^{14}$ This finding is crucial in achieving and understanding regarding the awareness and perception of PMS amongst women.

On assessing the clinical variables, most of students attained their menarche at the age of $12-15$ years $(89.7 \%)$ which was similar to the study done by Yashjoshi et al.,2016, ${ }^{15}$ reported that $51.66 \%$ of students had attained their menarche at the age of $11-13$ years. Moreover, majority of the students showed the duration of menses for about 3-5 days and the menstrual interval for about 24-35 days which was in the percentage of $68.9 \%$ and $95.1 \%$ respectively. These characteristics showed a pooling similarity with the study done by Yashjoshi et al.,2016, ${ }^{15}$ reported that $60 \%$ had the duration of menses for 4-5 days and Mandal R et al.,2015, ${ }^{14}$ reported $50 \%$ of students with regular menstrual interval.

PMS is usually described as a constellation of both somatic and affective symptoms manifesting prior to the occurrence of menstruation and resolving with the onset of menstruation or within few days of menstruation. Our study determined that the most frequent somatic symptoms were joint and muscle pain (44.9\%). The most frequent affective symptoms included angry outbursts (50.7\%), irritability (40.4\%) and depression (31.6\%) which was similar to previously reported findings done by Mandal $\mathrm{R}$ et al.,2015 ${ }^{14}$ and Mohib et al.,2018, ${ }^{16}$ that they showed irritability, anger and depression as their major symptoms. This result also lines up with the study done by Bhuvaneswari et al. $2019,{ }^{17}$ who explained that body, joint and muscle ache were one of their major symptoms. It is no surprise that PMS causes significant effects not only on women's normal daily routines but also on their occupation and social life. The present study reported that the most frequently interfered activities were studies (39.1\%), home responsibilities (27.6\%) and work (25.3\%). These findings were consistent with the study done by Madhu Gupta $\underline{e t}$ al.,2019, ${ }^{18}$ who reported studies as their interfered factor and Muralidhar Swami et al.,2017, ${ }^{19}$ who showed school and work efficacy as their interfered factors. It is also line up with the study done by Deepali Bansal et al.,2019, ${ }^{20}$ which included home responsibilities as one of their major interfered factors.

The majority of women in our study were aware of PMS and were using successful preventing and coping measures, a significant proportions of college students were using adaptive coping behaviours represented by lying down using pillow (53.8\%), taking hot/cold drink (37.8\%) and using hot bags (24.9\%), which is similar to the findings reported by Madhu Gupta et al.,2019, ${ }^{18}$ which stated that lying down in supine position and hot fomentation were the major coping behaviours. In addition, it is also similar to the study done by Amal Ahmed Hafez et al.,2015, ${ }^{21}$ which reported taking hot/cold drinks as their prominent coping behavior. However, 23.1\% reported that they have accepted PMS as a natural process and they take no treatment to relieve the symptoms. The findings could be explained by the fact that the condemnation in our society has created an equally negative attitude in young females towards menstruation and related matters; this has created hesitancy in consulting a doctor or seeking treatment for it, as they do not consider PMS a serious issue but just a normal part of their lives.

\section{CONCLUSION}

Our study determined that, the prevalence of PMS is about $40 \%$ among South Indian College students. It had caused debilitating effects on women's quality of life, work production and educational activities. Although, a predominant number of adults were adopting various coping measure to overcome the effect of PMS, there remains a considerable deficiency of knowledge about the

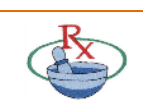


necessity to consult a doctor or seek any treatment for their symptoms. Therefore, it is obviously important to educate the young women about the need to track the premenstrual syndrome so as to seek further medical advice. Hence educational sessions and workshops concerning PMS must be conducted to disseminate more information. Further studies must be taken up to find out prevalence of PMS using PMS self-evaluation tool and ACOG criteria among the general population and other professionals.

Acknowledgment: The authors are very much grateful to all participants of the study for their kind cooperation.

\section{ABBREVIATIONS}

PMS: Premenstrual syndrome; PMD: Premenstrual disorder; ACOG: American College of Obstetricians and Gynecologists; IU: International unit; SSRI: Selective serotonin reuptake inhibitors; NSAIDs: Non-steroidal antiinflammatory drugs; GnRH: Gonadotropin releasing hormone.

\section{REFERENCES}

1. Zegeye DT, Megabiaw B, Mulu A. Age at menarche and the menstrual pattern of secondary school adolescents in northwest Ethiopia. Biomed Central Womens Health. 2009;9:29-32.

2. Serff L, Fritz MA. Menstrual disorder. Clinical gynecologic endocrinology and infertile. 8th ed. Philadelphia: Lippincott Williams and Wilkins; 2011. p. 568-78.

3. ACOG practice bulletin. Premenstrual syndrome. Clinical management guideline for obstetrician- gynecologists. J Obstet Gynaecol. 2001;73:183-91.

4. Cheng SH, Sun ZJ, Lee IH, Chih CC, Chen KC, Lin SH, et al. Perception of premenstrual syndrome and altitude of evaluations of work performance among incoming university female students. Biomed J. 2015;38(2):167-72. doi: 10.4103/2319-4170.138319, PMID 25179727.

5. Shershah S, Morrison JJ, Jafarey S. Prevalence of premenstrual syndrome in Pakistani women. J Pak Med Assoc. 1991;41(5):101-3. PMID 1861351.

6. Biggs WS, Demuth RH. Premenstrual syndrome and Premenstrual dysphoric disorder. Am Fam Physician. 2011;84(8):918-24. PMID 22010771.

7. Baker $\mathrm{L}, \mathrm{O}^{\prime}$ Brien PMS. Premenstrual syndrome (PMS): a perimenopausal perspective. Maturitas. 2012;72(2):121-5. doi: 10.1016/i.maturitas.2012.03.007, PMID 22534048.

8. Chaturvedi SK, Chandra PS, Issac MK, Sudarshan CY, Beena $\mathrm{MB}$, Sarmukkadam SB, et al. Premenstrual experiences: the four profiles and factorial patterns. J Psychosom Obstet Gynaecol. 1993;14(3):223-35. doi $\underline{10.3109 / 01674829309084444}$, PMID 8261031.
9. Braverman P K. Premenstrual syndrome and Premenstrual dysphoric disorder. J Pediatr Adolesc Gynecol. 2007;20(1):312. doi: 10.1016/i.jpag.2006.10.007, PMID 17289510.

10. American College of Obstetricians and Gynecologists. Guidelines for women's health care: A resource manual. 4thed. Washington, DC: American College of Obstetricians and Gynecologists; 2014. p. 607-13.

11. American College of Obstetricians and Gynecologists [ACOG] practice bulletin. ACOG PRACTICE BULLETIN. Int J Gynecol Obstet. 2001;73(2):183-91. doi: 10.1016/S00207292(01)00400-3.

12. O'Brien P M. The premenstrual syndrome. A review. J Reprod Med. 1985;30(2):113-26. PMID 3884803.

13. Seedhom AE, Mohammed ES, Mahfouz EM. Life style factors associated with premenstrual syndrome among el-Minia University students, Egypt. ISRN Public Health. 2013;2013:16. doi: $10.1155 / 2013 / 617123$.

14. Mandal R, Sarkar A, Ghorai S. A study on premenstrual syndrome among adolescent girl students in an urban area of West Bengal. Int J Reprod Contracept Obstet Gynecol;015(4 (4)):1012-5. doi: 10.18203/2320-1770.ijrcog20150417.

15. Mahadalkar YP, Rincy R. A study to assess the premenstrual symptoms experienced by college going students in selected area of Pune. Innovational J Nurs Healthc (IJNH). 2016;2(2):413-9.

16. Mohib A, Zafar A, Najam A, Tanveer H, Rehman R. Premenstrual syndrome: existence, knowledge, and attitude among female university students in Karachi. Cureus. 2018;10(3):e2290. doi: 10.7759/cureus.2290, PMID 29744256.

17. Bhuvaneswari K, Rabindran P, Bharadwaj B. Prevalence of premenstrual syndrome and its impact on quality of life among selected college students in Puducherry. Natl Med J India. 2019;32(1):17-9. doi: 10.4103/0970-258X.272109, PMID $\underline{31823933}$.

18. Gupta Madhu, Dua Devakshi, Kaur Harsheen, Grover Sandeep. Prevalence of premenstrual dysphoric disorder among school-going adolescent girls. Ind Psychiatry J. 2019;28(2):198-202. doi: 10.4103/ipj.ipj 79 19, PMID 33223711.

19. Swami $M$, Narain $M$, Kanwal $K$, Mishra $M$, Singh $S$. Premenstrual syndrome: correlation and Functional impairment. J Mahatma Gandhi Univ. Med Sci Technol. 2017;2(1):18-22.

20. Bansal D, Raman R, Rao TSS. Premenstrual Dysphoric disorder: ranking the symptoms and Severity in Indian College Students.J Psychosexual Health. 2019;1(2):159-63. doi: $10.1177 / 2631831819827183$.

21. Hafez AA, Ahmed SM, Entesarl M. Assessing the premenstrual syndrome and coping behaviours among female nursing students. Al-Azhar Assiut Med J. 2015;13(4):178-84.

Source of Support: The author(s) received no financial support for the research, authorship, and/or publication of this article.

Conflict of Interest: The author(s) declared no potential conflicts of interest with respect to the research, authorship, and/or publication of this article.

For any question relates to this article, please reach us at: globalresearchonline@rediffmail.com

New manuscripts for publication can be submitted at: submit@globalresearchonline.net and submit_ijpsrr@rediffmail.com 